\title{
Estudo de p27, p21, p16 em epitélio escamoso normal, papiloma escamoso e carcinoma de células escamosas da cavidade oral
}

\author{
Comparative analysis of the immunohistochemistry expression of p27, p21WAF/Cip1, and p16INK4a in oral \\ normal epithelium, squamous papilloma and squamous cell carcinoma
}

Ana Beatriz Piazza Queiroz'; Gustavo Rubino de Azevedo Focchi²; Thiago Simão Gomes³; Cristine Dobo4; Celina Tizuko Fujiyama Oshima

unitermos
Carcinoma de células
escamosas
Papiloma de células
escamosas
Imuno-histoquímica
Proteína oncogênica p21
Inibidor de quinase
dependente de ciclina p27
Genes p16

\section{resumo}

Introdução e objetivo: O tipo de câncer oral mais frequente é o carcinoma de células escamosas, que corresponde a $95 \%$ dos $\operatorname{casos}^{(9)}$. O papiloma escamoso oral é uma neoplasia benigna normalmente associada à infecção pelo papilomavírus humano (HPV) ${ }^{(21)}$. A análise da literatura mostra alterações nos genes reguladores do ciclo celular p27, p21WAF/Cip1 e p16INK4a, porém sem uma definição de seus papéis na carcinogênese oral. O objetivo foi caracterizar imuno-histoquimicamente p27, p21WAF/Cip1 e p16NK4a em epitélio escamoso normal, papilomas escamosos e carcinomas de células escamosas da cavidade oral. Métodos: Imuno-histoquímica para p27, p21WAF/Cip1 e p16NK4a em 32 casos de epitélio escamoso normal, 30 casos de papiloma escamoso e 34 de carcinoma de células escamosas da cavidade oral. Resultados: p27: 97,06\% dos casos de carcinoma de células escamosas apresentaram imunopositividade focal. O grupo papiloma escamoso apresentou 33,33\% e o grupo controle, 18,75\%. p21WAF/Cip1: 100\% de imunopositividade focal tanto no grupo controle como no grupo carcinoma de células escamosas, e $90 \%$ no grupo papiloma escamoso. p16INK4a: 100\% de imunopositividade focal para os grupos controle e papiloma escamoso, e $94 \%$ para o grupo carcinoma de células escamosas. Conclusão: Imuno-histoquimicamente demonstrouse diferença significativa para p27 quando feita comparação dos grupos controle e papiloma escamoso com o grupo carcinoma de células escamosas. O p21WAF/Cip1 não demonstrou poder de diferenciar os grupos analisados. O p16INK4a apresentou imunopositividade difusa em uma minoria dos casos do grupo carcinoma de células escamosas. O grupo papiloma escamoso se comportou de maneira similar ao grupo controle em relação aos três marcadores. abstract

Introduction: The most frequent type of oral cancer is the squamous cell carcinoma, which corresponds to 95\% of the cases ${ }^{(9)}$. The oral squamous papilloma is a benign neoplasia, commonly associated with infections caused by the human papilloma virus(21). The analysis of medical literature shows changes in cell cycle regulatory genes (p27, p21WAF/Cip1 and p16INK4a), but does not define their roles in oral carcinogenesis. Objective: Characterize the immuno-histochemical expression of p27, p21WAF/Cip1 and p16INK4a in oral normal squamous epithelium, oral squamous papilloma and oral squamous cell carcinoma. Methods: Immuno-histochemical evaluation of p27, p21WAF/Cip1 and p16INK4a in 32 samples of oral normal squamous epithelium, 30 of oral squamous papilloma and 34 of oral squamous cell carcinoma. Results: $97.06 \%$ of the oral squamous cell carcinoma group, $33.33 \%$ of the squamous papilloma group and $18.75 \%$ of the control group showed focal immunopositivity for $27.100 \%$ of both control and oral squamous cell carcinoma groups and $90 \%$ of the oral squamous papilloma group showed focal immunopositivity for p21WAF/Cip1. 100\% of both control and oral squamous papilloma groups and $94 \%$ of the oral squamous cell carcinoma group showed focal immunopositivity for p16INK4a. Conclusions: The study revealed a statistically significant difference for 277 expression when comparing the control and oral squamous papilloma groups with the oral squamous cell carcinoma group. p21WAF/Cip1 did not prove to be useful to differentiate the groups. p16INK4a showed diffuse immunopositivity in a minority of the oral squamous cell carcinoma cases. The oral squamous papilloma group behaved similarly to the control group as to the three markers. key words

Squamous cell carcinoma

Squamous papilloma

Immunohistochemistry

Cyclin-dependent kinase inhibitor p27

Oncogene protein p21

Cyclin-dependent kinase inhibitor $p 16$

1. Mestra em Ciências da Saúde; membro do Programa de Pós-Graduação do Departamento de Patologia da Escola Paulista de Medicina da Universidade Federal de São Paulo (EPM/UNIFESP).

2. Doutor; professor adjunto de Patologia da EPM/UNIFESP.

3. Mestre em Ciências da Saúde; membro do Programa de Pós-Graduação do Departamento de Patologia da EPM/UNIFESP.

4. Doutora em Ciências da Saúde; membro do Programa de Pós-Graduação do Departamento de Patologia da EPM/UNIFESP.

5. Doutora; professora convidada da disciplina de Patologia da EPM/UNIFESP. 


\section{Introdução}

Ao longo dos últimos anos, o comportamento biológico de diversas afecções e do fenótipo maligno de várias neoplasias tem sido investigado por uma gama de técnicas nas áreas médica e odontológica, entre elas: contagem de figuras de mitose, avaliação das regiões organizadoras nucleolares (AgNORs), incorporação de timidina tritiada e autorradiografia, 5-bromodeoxiuridina (Brdu), citometria de fluxo, além de novas técnicas de genética e biologia molecular ${ }^{(5,26)}$. Atualmente, o método imuno-histoquímico é amplamente utilizado nesse sentido, sendo o antígeno nuclear de proliferação celular (PCNA), o Ki-67 e a p53 os mais estudados(5, 26).

Nos tecidos adultos, o tamanho das populações celulares é determinado pelos índices de proliferação, diferenciação e morte celular por apoptose. A proliferação celular pode ser influenciada por condições fisiológicas e patológicas, sendo amplamente controlada por sinais, solúveis ou contatodependentes, de microambientes que agem estimulando-a ou inibindo-a. O mecanismo de proliferação celular mais importante é a conversão de células quiescentes em proliferativas. O recrutamento das células quiescentes e a progressão do ciclo celular requerem sinais estimulantes para sobrepujar a inibição fisiológica da proliferação celular ${ }^{(23)}$.

As atividades do ciclo celular são comandadas por ciclinas, cinases dependentes de ciclina (CDK-s) e seus inibidores. Durante todo o ciclo, a função das ciclinas é ativar as CDK-s, sendo que seus níveis caem após exercerem essa função(23).

A atividade dos complexos ciclina-CDK é regulada por fatores chamados inibidores de CDK-s. Existem duas classes principais de inibidores: as famílias Cip/Kip e INK-4/ARF. Dentro da família Cip/Kip destacam-se p21, p27 e p53 e, pertencentes à família INK-4/ARF, p16 e p14. Estes inibidores funcionam como supressores do tumor $\mathrm{e}$ estão frequentemente alterados em tumores. Eles se ligam aos complexos ciclinas/CDK-s e os inativam. A proteína p16INK4a compete com a ciclina D na ligação com CDK-4 e inibe a capacidade do complexo de fosforilar pRb, causando uma parada no ciclo no final de G1. A atividade transcricional de p21 WAF/Cip1 está sob o controle da proteína p53. A p21 WAF/Cip1 também irá competir com a ciclina $D$ com a mesma intenção de provocar a parada no ciclo celular. A p27 responde aos supressores de crescimento e irá competir com o complexo ciclina E/CDK-2, também provocando uma parada do ciclo celular no ponto de restrição $\mathrm{G} 1 / \mathrm{S}$.
O tipo histológico de câncer de boca mais frequente é o carcinoma de células escamosas ou carcinoma epidermoide, correspondendo a $90 \%$ a $95 \%$ dos $\operatorname{casos}^{(9,20)}$.

O papiloma escamoso oral é uma neoplasia benigna de origem epitelial, com crescimento exofítico, frequente principalmente na língua e no palato, e normalmente associada à infecção pelo HPV, mais frequentemente aos tipos 6 e 11. É o tumor benigno mais comum da cavidade oral, e o seu potencial biológico para transformação maligna ainda está em estudo ${ }^{(21)}$.

A análise dos dados da literatura mostra alterações nos referidos genes reguladores do ciclo celular: P27, P21 e P16, porém sem uma definição de seus devidos papéis na carcinogênese oral.

Normalmente os níveis de p27 apresentam-se aumentados em células quiescentes e caem rapidamente após estimulação por mitógenos. A baixa regulação de p27 tem sido relacionada com pior prognóstico para pacientes com diversos carcinomas, incluindo o carcinoma de células escamosas oral, sendo relacionada direta ou indiretamente com a invasão e também com a proliferação celular anormal. Ainda não é claro, no entanto, em qual estágio da carcinogênese oral ocorre a subregulação dessa proteína ${ }^{(14)}$.

A proteína p21 WAF/Cip1 é um efetor crítico da via p53-dependente e provoca uma parada no ciclo celular pela inibição da cinase dependente de ciclina. Portanto, p21 WAF/Cip1 exerce papel central na apoptose, e também está relacionada com a diferenciação terminal do epitélio escamoso ${ }^{(19)}$. Alguns estudos têm mostrado que, no processo de carcinogênese oral, a expressão da p21 WAF/Cip1 pode também ser regulada por vias independentes de p53.

A alta incidência de inativação do gene CDKN2A no câncer bucal indica a sua grande importância na carcinogênese. Porém, até o presente momento, não se sabe o valor desse achado ${ }^{(18)}$. Alguns estudos associaram alterações de p16INK4a a menor sobrevida, maior probabilidade de recorrência e aparecimento de metástases regionais em carcinomas espinocelulares orais ${ }^{(5)}$.

Considerando a escassez de estudos sobre o papiloma escamoso oral, este estudo se propôs a melhor estudar esta lesão e seu eventual potencial carcinogênico.

\section{Materiais e métodos}

\section{Materiais}

Estudo retrospectivo de amostras de tecido de mucosa oral em blocos de parafina do arquivo do Departamento de 
Patologia da Escola Paulista de Medicina da Universidade Federal de São Paulo (EPM/UNIFESP), 1996 a 2006. Este projeto de pesquisa foi aprovado pelo Comitê de Ética em Pesquisa da UNIFESP.

A comparação foi realizada entre os seguintes grupos:

- 34 amostras de carcinoma de células escamosas;

- 30 amostras de papiloma escamoso;

- 32 amostras obtidas a partir de necropsias de pacientes adultos do Serviço de Verificação de Óbitos do Departamento de Patologia da EPM/UNIFESP.

\section{Critérios de inclusão}

Ambos os sexos, acima de 40 anos de idade e tabagistas.

\section{Critérios de exclusão}

Pacientes que apresentaram mais de uma patologia oral e/ou presença de qualquer doença sistêmica.

\section{Imuno-histoquímica}

Os processos de fixação, embebição em parafina, cortes e coloração pela hematoxilina-eosina seguiram os procedimentos de rotina da técnica histológica do Departamento de patologia da UNIFESP/EPM ${ }^{(17)}$.

Dos blocos representativos de cada caso foram realizados cortes de aproximadamente $3 \mathrm{~mm}$ de espessura, aderidos em lâminas tratadas com 3-aminopropiltrietoxisilano (Sigma, Co. - USA-A3648) e deixadas em estufa a $60^{\circ} \mathrm{C}$ por 12 horas.

As lâminas foram desparafinizadas por dois banhos de xilol à temperatura ambiente por 15 minutos cada e hidratação em concentrações decrescentes de etanol até água corrente. A recuperação antigênica foi realizada com irradiação no forno de micro-ondas submersos em tampão citrato, pH 6 em alta potência por 20 minutos (ou com a utilização de panela a vapor por 30 minutos). Após resfriamento das lâminas por 20 minutos à temperatura ambiente e posterior lavagem em água corrente por 5 minutos, foi realizado o bloqueio da peroxidase endógena utilizando-se solução de peróxido de hidrogênio a $3 \%\left(\mathrm{H}_{2} \mathrm{O}_{2}\right.$ a 10 volumes), em quatro banhos de 5 minutos cada, lavando-se em seguida em água corrente e solução tampão salina de fosfato (PBS) (pH 7,4).

A incubação com os anticorpos primários anti-p16 (clone ab 7 16PO7 - Neomarkers, Fremont, CA, USA.) diluídos em título preestabelecido 1:50; anti-p21 (p21WAF/Cip1 Monoclonal Mouse Anti-Human SX118) na diluição1:50; e p27 (p27Kip1 Monoclonal Mouse Anti-Human SX53G8) na diluição 1:100 foi realizada em câmara úmida a $4^{\circ} \mathrm{C}$ por 18 horas.

Depois da lavagem em PBS por três vezes, realizou-se a incubação com anticorpo secundário biotinilado do kit Dako LSAB-HRP, em câmara úmida à temperatura ambiente por 30 minutos. Após a nova lavagem em PBS $(\mathrm{pH} 7,4)$ por três vezes, foi feita a incubação com o conjugado estreptoavidina-peroxidase do kit Dako LSAB-HRP por 30 minutos, em câmara úmida.

Em seguida realizou-se a lavagem com PBS ( $\mathrm{pH} 7,4)$, com três trocas de 5 minutos cada e revelação das lâminas com $60 \mathrm{mg}$ de diaminobenzidina (Dab) (Sigma, USA) diluído em $100 \mathrm{ml}$ de PBS (pH 7,4), acrescido de $1 \mathrm{ml}$ de peróxido de hidrogênio a $3 \%$ à temperatura ambiente por 5 minutos.

Após bloqueio da reação com lavagem extensiva em água corrente, foi realizada a contracoloração com hematoxilina de Harris por 1 minuto. Foi feita lavagem em água corrente, em concentração crescente até etanol absoluto, diafanização em três banhos de xilol e montagem das lâminas com lamínulas em resina Entellan (Sigma) para análise em microscopia ótica comum.

\section{Critério de positividade da coloração imuno- histoquímica}

O padrão de imunocoloração para p16, p21 e p27 foi considerado positivo quando da presença de coloração marrom-acastanhada, nuclear (p21 e p27) e citoplasmática e nuclear ( 16 ), sendo quantificado nas seguintes categorias, de acordo com a intensidade da marcação $0^{(11)}$ :

- negativo: não apresentou células coradas;

- positivo focal: até $25 \%$ das células coradas (+);

- positivo moderado: mais de $25 \%$ até $50 \%$ das células coradas (++);

- positivo difuso: mais de 50\% das células coradas (+++).

\section{Análise estatística}

Para análise das tabelas de contingência foi proposto o teste do qui-quadrado $\left(\chi^{2}\right)$, observando-se as restrições de Cochran, mas, como estas estavam presentes, não seria possível a aplicação do teste estatístico.

Foi proposta então a transformação das tabelas de contingência em tabelas de associação para efeito de análise. Em razão das semelhanças entre os resultados dos grupos controle e papiloma, eles foram associados em um único grupo. 


\section{Resultados}

Na Tabela 1, observa-se imunopositividade difusa para p27 em 90,63\% dos casos no grupo controle e em $81,25 \%$ dos casos no grupo papiloma escamoso. Em contrapartida, o grupo carcinoma de células escamosas apresentou imunopositividade focal em $97,06 \%$ dos casos.

Verificou-se, a partir desses resultados, o comportamento de p27, expresso no grupo controle e nos casos de papiloma com perda de imunoexpressão no grupo carcinoma de células escamosas.

Na Tabela 2, quando os grupos controle e papiloma escamoso foram analisados conjuntamente, em comparação com o grupo carcinoma de células escamosas, foi demonstrada a significância estatística da imunoexpressão de $\mathrm{p} 27$.

Na Tabela 3, os grupos controle e carcinoma de células escamosas tiveram $100 \%$ de imunopositividade focal e apenas $10 \%$ do grupo papiloma tiveram imunopositividade difusa para p21WAF. Não foi observada significância estatística (Tabela 4).

Na Tabela 5, observa-se que $100 \%$ dos casos dos grupos controle e papiloma escamoso mostraram imunopositividade focal para p16. Em relação ao grupo carcinoma espinocelular, em 94\% dos casos houve imunopositividade focal e em $6 \%$, imunopositividade difusa para o referido marcador.

Em relação à Tabela 6 pode-se afirmar que p16 não apresentou significância estatística.

Expressão imuno-histoquímica de p27 em epitélio normal, papiloma escamoso e carcinoma de

Tabela 1 células escamosas

\begin{tabular}{llllcllll}
\hline & & Controle & \multicolumn{3}{c}{ Papiloma } & \multicolumn{2}{c}{ CEC } & \multicolumn{2}{c}{ Total } \\
O ou $(+)$ ou $(++)$ & 6 & $18,75 \%$ & 10 & $33,33 \%$ & 33 & $97,06 \%$ & 49 & $51,04 \%$ \\
$(+++)$ & 26 & $81,25 \%$ & 20 & $66,67 \%$ & 1 & $2,94 \%$ & 47 & $48,96 \%$ \\
Total & 32 & $100 \%$ & 30 & $100 \%$ & 34 & $100 \%$ & 96 & $100 \%$
\end{tabular}

Tabela 2

Análise estatística da imunoexpressão de p27 nos grupos controle e papiloma escamoso em

\begin{tabular}{llllllc} 
Tabela 2 & \multicolumn{6}{c}{ comparação com o grupo carcinoma de células escamosas } \\
\hline \multicolumn{7}{c}{ Contr/Pap } \\
O ou (+) ou (++) & 16 & $25,81 \%$ & 33 & $97,06 \%$ & 49 & $51,04 \%$ \\
$(+++)$ & 46 & $74,19 \%$ & 1 & $2,94 \%$ & 47 & $48,96 \%$ \\
Total & 62 & $100 \%$ & 34 & $100 \%$ & 96 & $100 \%$
\end{tabular}

(Yates) $=41,806^{*} ; p<0,0001$.

\begin{tabular}{|c|c|c|c|c|c|c|c|c|}
\hline \multirow[b]{2}{*}{ O ou $(+)$ ou $(++)$} & \multicolumn{2}{|c|}{ Controle } & \multicolumn{2}{|c|}{ Papiloma } & \multicolumn{2}{|c|}{ CEC } & \multicolumn{2}{|r|}{ Total } \\
\hline & 32 & $100 \%$ & 27 & $90 \%$ & 34 & $100 \%$ & 93 & $96,88 \%$ \\
\hline$(+++)$ & 0 & $0 \%$ & 3 & $10 \%$ & 0 & $0 \%$ & 3 & $3,13 \%$ \\
\hline Total & 32 & $100 \%$ & 30 & $100 \%$ & 34 & $100 \%$ & 96 & $100 \%$ \\
\hline
\end{tabular}

Expressão imuno-histoquímica de p21 em epitélio normal, papiloma escamoso e carcinoma de células escamosas 
Análise estatística da imunoexpressão de p21 nos grupos controle e papiloma escamoso

\begin{tabular}{lllllll} 
Tabela 4 & \multicolumn{6}{c}{ em comparação com o grupo carcinoma de células escamosas } \\
\hline \multicolumn{7}{c}{ Contr/Pap } \\
O ou (+) ou (++) & 59 & $95,16 \%$ & 34 & $100 \%$ & 93 & $96,88 \%$ \\
$(+++)$ & 3 & $4,84 \%$ & 0 & $0 \%$ & 3 & $3,13 \%$ \\
Total & 62 & $100 \%$ & 34 & $100 \%$ & 96 & $100 \%$
\end{tabular}

Teste de Fisher; $p=0,265$ N.S.

Tabela 5

\begin{tabular}{lllllllll}
\hline & \multicolumn{2}{c}{ Controle } & \multicolumn{3}{c}{ Papiloma } & \multicolumn{2}{c}{ CE } & \multicolumn{2}{c}{ Total } \\
O ou $(+)$ ou $(++)$ & 32 & $100 \%$ & 30 & $100 \%$ & 32 & $94 \%$ & 94 & $98 \%$ \\
$(+++)$ & 0 & 0 & 0 & 0 & 2 & $6 \%$ & 2 & $2 \%$ \\
Total & 32 & $100 \%$ & 30 & $100 \%$ & 34 & $100 \%$ & 96 & $100 \%$
\end{tabular}

\section{Expressão imuno-histoquímica de p16 em epitélio normal, papiloma escamoso e} carcinoma de células escamosas

\section{Análise estatística da imunoexpressão de p16 nos grupos controle e papiloma escamoso em}

Tabela 6

\begin{tabular}{lllllll}
\hline & \multicolumn{3}{c}{ Contr/Pap } & \multicolumn{2}{c}{ CEC } & Total \\
O ou $(+)$ ou $(++)$ & 62 & $100 \%$ & 32 & $94 \%$ & 94 & $98 \%$ \\
$(+++)$ & 0 & $0 \%$ & 2 & $6 \%$ & 2 & $2 \%$ \\
Total & 62 & $100 \%$ & 34 & $100 \%$ & 96 & $100 \%$
\end{tabular}

Teste de Fisher; $p=0,123$ N.S.

\section{Discussão}

A transformação de células normais em malignas é alcançada por um processo de múltiplas etapas associadas ao acúmulo de sucessivas alterações genéticas tanto em oncogenes quanto em genes supressores de tumor. A origem e a progressão do câncer podem ser causadas por anormalidades em vários reguladores - positivos e negativos - do ciclo celular ${ }^{(13)}$. A progressão do ciclo celular é regulada positivamente por múltiplas ciclinas e cinases dependentes de ciclina, e negativamente por um número de inibidores de cinases dependentes de ciclina, incluindo p16, p21 e p27(23).

O alto índice de expressão de p27 no epitélio escamoso oral indica seu papel na manutenção dos mecanismos envolvidos no ciclo celular em tecidos normais. De fato, em carcinomas espinocelulares, a expressão de p27 pode estar relacionada com melhor prognóstico ${ }^{(14,16)}$.
O epitélio normal apresenta expressão nuclear de p27 aumentada ${ }^{(10,16)}$, notada em células maduras superficiais diferenciadas ${ }^{(2)}$. No presente estudo, $81,25 \%$ dos casos do grupo controle apresentaram a proteína p27 expressa em padrão similar aos dados da literatura. Dessa forma pode-se demonstrar a importância de p27 na regulação do ciclo celular em células normais e sua relação com o processo de maturação e diferenciação celulares.

A redução da expressão de p27 foi demonstrada na fase inicial de invasão em carcinomas espinocelulares orais, exercendo importante papel na proliferação anormal, devido à perda da regulação do ciclo celular e podendo, ainda, correlacionar-se com a habilidade de invasão tecidual pelas células neoplásicas ${ }^{(10,14,16)}$.

No presente estudo, observamos expressão de p27 diminuída (menos de $50 \%$ das células) em $97,06 \%$ dos casos de carcinoma de células escamosas. 
Tais achados demonstram a relação da proteína p27 com o processo de maturação celular: a p27 foi expressa em células maduras e a perda de maturação das células foi acompanhada pela diminuição da expressão da proteína. Em células mais diferenciadas, portanto mais maduras, há maior expressão dessa proteína, o mesmo não ocorrendo em células pouco diferenciadas, imaturas, tanto no epitélio normal quanto no neoplásico.

Os carcinomas espinocelulares pouco diferenciados não apresentaram expressão da p27, provavelmente pela escassez ou ausência de células maduras neste tipo de lesão. Em relação aos carcinomas moderadamente e bem diferenciados, houve expressão considerável dessa proteína, relacionada com a presença crescente de células maduras.

Em nosso estudo houve diferença estatisticamente significativa na imunoexpressão de p27 quando comparados os grupo controle e papiloma com o grupo carcinoma de células escamosas.

A expressão de p27 foi menor em carcinomas espinocelulares menos diferenciados, tendo sido observada em ninhos de células tumorais mais diferenciadas, de acordo com estudos anteriores ${ }^{(14,16,25)}$.

$\mathrm{Na}$ gênese do carcinoma de células escamosas oral, também estão descritas alterações do regulador do ciclo celular p21(7).

Propõe-se que a expressão da p21 se correlaciona positivamente com a proliferação celular, enquanto a expressão da p27, com a diferenciação celular. A análise simultânea da expressão da p27 e da p21 pode levar à melhor compreensão da progressão do carcinoma de células escamosas ${ }^{(2)}$.

A expressão de p21 em epitélio escamoso histologicamente normal é descrita em células imaturas, basais e suprabasais, mais indiferenciadas ${ }^{(2)}$, achado também observado no nosso grupo controle. No epitélio normal não foi encontrado aumento da expressão da p21 ${ }^{(4,15,30)}$. Nosso estudo observou a expressão de p21 no terço basal do epitélio normal, ou seja, maior expressão em células imaturas e indiferenciadas. A p21 não foi encontrada em células superficiais maduras.

Segundo Freer ${ }^{(4)}$, a expressão de p21 é geralmente restrita a células intermediárias da mucosa oral normal e de carcinomas bem diferenciados, não sendo detectada em lesões displásicas severas e em carcinomas espinocelulares pouco diferenciados. Esses resultados sugerem que a expressão da p21 é uma característica comum a tecidos diferenciados, tanto normais quanto neoplásicos, indicando que a p21 não é um avaliador útil de proliferação celular ou de potencial malignidade.
No estudo de $\mathrm{Hogmo}^{(8)}$, a expressão de p21 não se mostrou diferente no grupo de carcinomas espinocelulares em relação ao grupo controle. O mesmo achado foi compartilhado em nosso estudo.

Dos casos de carcinoma de células escamosas analisados, $100 \%$ tiveram menos que $50 \%$ das células coradas. Os carcinomas bem diferenciados apresentaram 100\% de casos com menos de $50 \%$ das células coradas.

Em nossos achados temos $100 \%$ de imunopositividade focal tanto no grupo controle como no grupo carcinoma de células escamosas. Dessa forma, não se pode afirmar que p21 possua a capacidade de predizer uma transformação maligna.

Produtos proteicos de genes supressores tumorais estão frequentemente envolvidos na regulação do ciclo celular. A mutação do gene p16 tem sido detectada com taxa relativamente alta em carcinomas espinocelulares

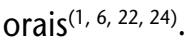

A hipermetilação, levando à inativação de alguns genes supressores de tumor, como o p16, tem sido ressaltada como um evento inicial no câncer de cabeça e pescoço ${ }^{(11,27-29)}$.

Em nosso estudo, o epitélio normal foi negativo, enquanto o epitélio atípico apresentou coloração irregular. Nenhum caso do grupo controle apresentou imunopositividade. Observou-se uma expressão focal ( $0 \%$ a $50 \%)$ da p16 em tecido não neoplásico e em alguns casos de lesões pré-invasivas. Os casos de carcinoma invasivo e displasias de alto grau apresentaram-se negativos para a p16, e apenas $6 \%$ dos casos de carcinoma de células escamosas exibiram imunopositividade difusa. Em alguns casos ocorreu expressão crescente da p16 associada à progressão histológica da lesão.

A hipótese mais consistente seria a de que $\mathrm{p} 16$ poderia sinalizar com muita precocidade indícios de uma possível transformação maligna, porém, por apresentar perda da expressão precocemente, talvez por hipermetilação, não consegue ainda se destacar como um bom marcador diagnóstico ou prognóstico.

Em relação aos papilomas escamosos orais, os achados de Fonseca ${ }^{(3)}$ sugerem que a taxa de proliferação celular em papilomas escamosos é maior que a das hiperplasias e menor que a dos carcinomas.

Em nosso estudo, os papilomas apresentaram expressão difusa da proteína p27 na maioria dos casos. Isso mostra que o papiloma escamoso, no caso da proteína p27, comporta-se semelhante ao tecido normal. Compa- 
rando este achado com os casos de carcinoma de células escamosas, temos $97,06 \%$ dos carcinomas espinocelulares com imunoexpressão de p27 diminuída, enquanto para os papilomas temos $66,67 \%$ de imunoexpressão aumentada. Isso demonstra uma relação inversa na imunoexpressão de p27 entre essas lesões.

No caso do gene $\mathrm{p} 21,10 \%$ dos casos de papiloma apresentaram imunopositividade em mais de $50 \%$ das células, enquanto o grupo controle não apresentou imunopositividade difusa. A expressão imuno-histoquímica deste mesmo gene para o carcinoma de células escamosas foi de $100 \%$ para os casos que apresentaram menos de $50 \%$ das células coradas.

Com relação à p16, nenhuma das amostras de papiloma escamoso demonstrou imunopositividade difusa, também se assemelhando ao padrão do epitélio normal, que apre- sentou o mesmo resultado. Em relação ao carcinoma de células escamosas, $6 \%$ dos casos apresentaram imunopositividade aumentada.

De acordo com nossos achados, é possível afirmar que imuno-histoquimicamente o papiloma escamoso se comportou de maneira similar ao grupo controle e se distanciou visivelmente do grupo composto por carcinomas. Este padrão foi mantido em relação aos três marcadores.

\section{Agradecimento}

Este trabalho foi possível graças ao apoio financeiro da Coordenação de Aperfeiçoamento de Pessoal de Nível Superior (CAPES).

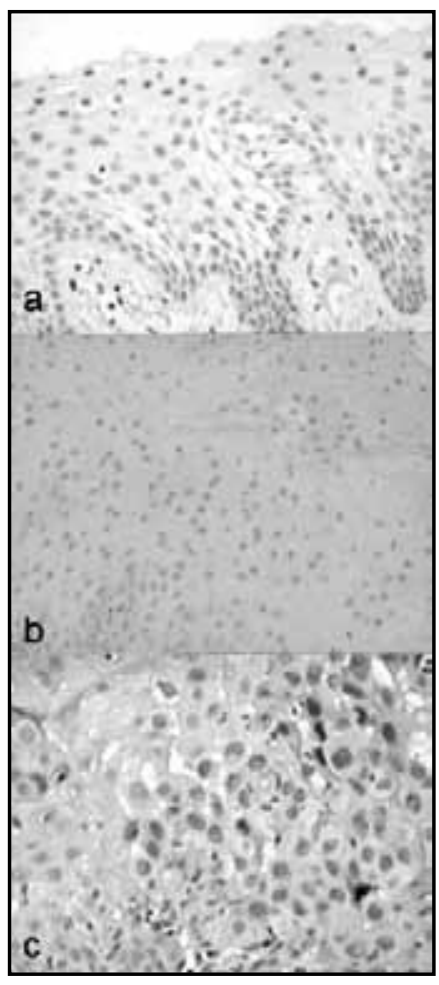

Figura 1 - Expressão imuno-histoquímica de p27 em epitélio escamoso oral normal, papiloma escamoso oral e carcinoma espinocelular oral. A: epitélio escamoso oral normal. Notar positividade nuclear em células dos terços superficial e intermediário associada a diferenciação e maturação epiteliais; B: papiloma escamoso oral. Notar positividade nuclear em células maduras associada à diferenciação e maturação epiteliais. C: carcinoma espinocelular oral. Notar positividade nuclear nas células mais diferenciadas (200x)

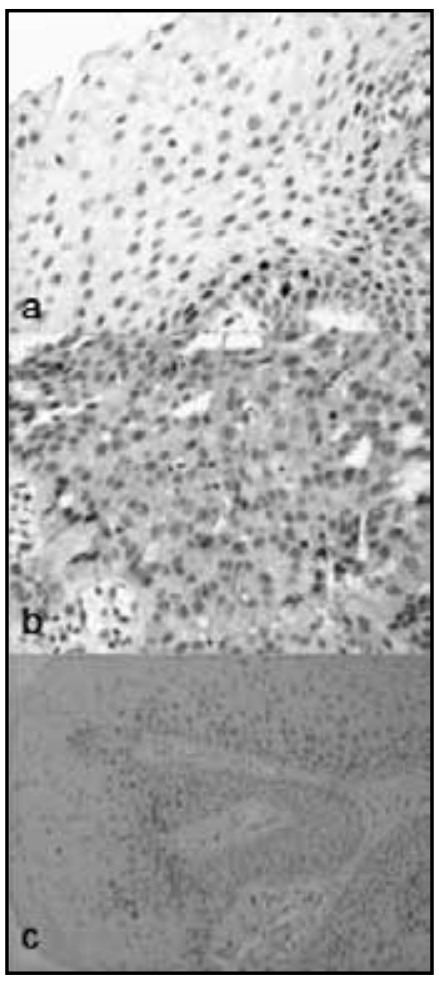

Figura 2 - Expressão imuno-histoquímica de p21 Waflipl em epitélio escamoso oral normal, papiloma escamoso oral e carcinoma espinocelular oral. A: epitélio escamoso oral normal. Notar positividade nuclear em células suprabasais imaturas no terço profundo do epitélio; B: papiloma escamoso oral. Notar positividade nuclear em células suprabasais imaturas no terço profundo do epitélio; C: carcinoma espinocelular oral. Notar positividade nuclear de distribuição aleatória em células com maior ou menor grau de diferenciação (200x)

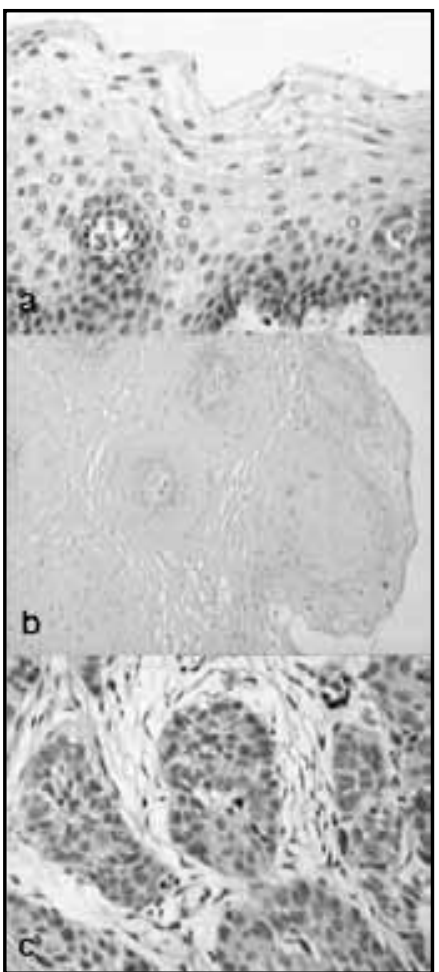

Figura 3 - Expressão imuno-histoquímica de p1 $6^{\text {INK4a }}$ em epitélio escamoso oral normal, papiloma escamoso oral e carcinoma espinocelular oral; A: epitélio escamoso oral normal. Notar negatividade em toda a extensão do epitélio; B: papiloma escamoso oral. Notar negatividade em toda a extensão do epitélio; C: carcinoma espinocelular oral. Notar negatividade das células neoplásicas (200x) 


\section{Referências}

1. BRADLEY, K. T.; BUDNICK, S. D.; LOGANI, S. Immunohistochemical detection of p16INK4a in dysplastic lesions of the oral cavity. Mod Pathol, v. 23, n. 2, p. 102-5, 2006.

2. $\mathrm{CHOI}, \mathrm{H}$. R. et al. Differential expression of cyclindependent kinase inhibitors (p27 and p21WAF/Cip1) and their relation to p53 and ki-67 in oral squamous tumorigenesis. Int J Oncol, v. 22, n. 2, p. 409-14, 2003.

3. FONSECA, L. M.; DO CARMO, M. A. AgNORs in hyperplasia, papilloma and oral squamous cell carcinoma. Braz Dent J, v, 11, n. 2, p. 105-10, 2000.

4. FREER, E. et al. Ras oncogene product expression in normal and malignant oral mucosa. Aust Dent J, v. 35, n. 2, p. 141-6, 1990.

5. GLEICH, L. L.; SALAMONE, F. N. Molecular genetics of head and neck cancer. Cancer Control, n. 9, p. 369-78, 2002.

6. GOLOGAN, O.; BARNERS, E. L.; HUNT, J. L. Potential diagnostic use of p16INK4A, a new marker that correlates with dysplasia in oral squamoproliferative lesions. Am J Surg Pathol, v. 29, n. 6, p. 792-6, 2005.

7. GOTO, M. et al. Loss of p21 WAF1/CIPI1 expression in invasive fronts of oral tongue squamous cell carcinomas is correlated with tumor progression and poor prognosis. Oncol Rep, v. 14, n. 4, p. 837-46, 2005.

8. HOGMO, A. et al. Preneoplastic oral lesions: the clinical value of image cytometry DNA analysis, p53 and p21/ WAF1 expression. Anticancer Res, v. 18, n. 5B, p. 3645-50, 1998.

9. INCA - Instituto Nacional do Câncer. Disponível em: <http:// www.inca.org.br/cancer/hpv.html>. Acesso em: 15 jan. 2007.

10. JORDAN, R. C.; BRADLEY, G.; SLINGERLAND, J. Reduced levels of the cell-cycle inhibitor p27kip1 in epithelial dysplasia and carcinoma of the oral cavity. Am J Pathol, v. 152, n. 2, p. 585-90, 1998.

11. KLAES, R. et al. Overexpression of p16INK4a as a specific marker for dysplastic and neoplastic epithelial cells of the cervix uteri. Int J Câncer, n. 92, p. 276-84, 2001.

12. KRESTY, L. A. et al. Alterations of p16 (INK4) and p14 (ARF) in patients with severe oral epithelial dysplasia. Cancer Res, v. 62, n. 18, p. 5295-300, 2002.

13. KUDO, Y. et al. Down-regulation of Cdk inhibitor p27 in oral squamous cell carcinoma. Oral Oncol, n. 41, p. 105-16, 2005.

14. KUDO, Y. et al. Reduced expression of p27 (kip1) correlates with an early stage of cancer invasion in oral squamous cell carcinoma. Cancer Lett, v. 151, n. 2, p. 217-22, 2000.

15. KUO, M. Y. et al. Elevated ras p21WAF/Cip1 expression in oral premalignant lesions and squamous cell carcinoma in Taiwan. J Oral Pathol Med, v. 24, n. 6, p. 255-60, 1995.
16. KUO, M. Y. et al. Prognostic role of p27(Kip1) expression in oral squamous cell carcinoma in Taiwan. Oral Oncol, v. 38, n. 2, p. 172-8, 2002.

17. MICHALANY, J. Técnica histológica em anatomia patológica. 3. ed. São Paulo: Michalany, 1998.

18. MULLIS, K. B. The unusual origin of the polymerase chain reaction. Scientific American, p. 56-65, 1990.

19. RALHAN, R. et al. Association between Polymorphism in p21WAF/Cip1 cyclin-dependent kinase inhibitor gene and human oral cancer. Clinical Cancer Research, n. 6, p. 2440-7, 2000.

20. REGEZI, J. A.; SCIUBA, J. J. Patologia bucal: correlações clinicopatológicas. Rio de Janeiro: Guanabara/Koogan, 1991.

21. RESZEC, J. et al. The expression of tumorigenesis makers in oral papilloma. Pol J Pathol, v. 53, n. 4, p. 195-200, 2002.

22. RIESE, U. et al. Tumor suppressor gene p16 (CDKN2A) mutation status and promoter inactivation in head and neck cancer. Int J Mol Med, v. 4, n. 1, p. 61-5, 1999.

23. ROBBINS, S.; COTRAN, R. Bases patológicas das doenças. Rio de Janeiro: Elsevier, 2005. p. 300-23.

24. SAITO, T.; NAKAJIMA, T; MOGI, K. Immunohistochemical analysis of cell cycle-associated proteins p16INK4a, pRb, p53, p27 and Ki-67 in oral cancer and precancer with special reference to verrucous carcinomas. Oral Pathol Med, v. 28, n. 5, p. 22632, 1999

25. SHINTANI, S. et al. Expression of cell cycle control proteins in normal epithelium, premalignant and malignant lesions of oral cavity. Oral Oncol, v. 38, n. 3, p. 23543, 2002.

26. SITTEL, C. et al. Prognostic significance of Ki-67 (MIB1), PCNA and p53 in cancer of the oropharynx and oral cavity. Oral Oncol, n. 35, p. 583-9, 1999.

27. SONI, S. et al. Alterations of rb pathway components are frequent events in patients with oral epithelial dysplasia and predict clinical outcome in patients with squamous cell carcinoma. Oncology, v. 68, n. 4-6, p. 314-25, 2005.

28. VON ZEIDLER, S. V. et al. Hypermethylation of the P16INK4a gene in normal oral mucosa of smokers. Int J Mol Med, v. 14, n. 5, p. 807, 2004.

29. YAKUSHIJI, T. et al. Over-expression of DNA methyltransferases and CDKN2 gene methylation status in squamous cell carcinoma of the oral cavity. Int J Oncol, v. 22, n. 6, p. 1201-7, 2003.

30. YANG, L.; JIN, Y.; SI, X. Expression of p21WAF/Cip1 and p185 in benign and malignant epithelia of cheek mucosa. Hua Xi Kou Qiang Yi Xue za Zhi, v. 16, n. 1, p. 20-2, 1998. 